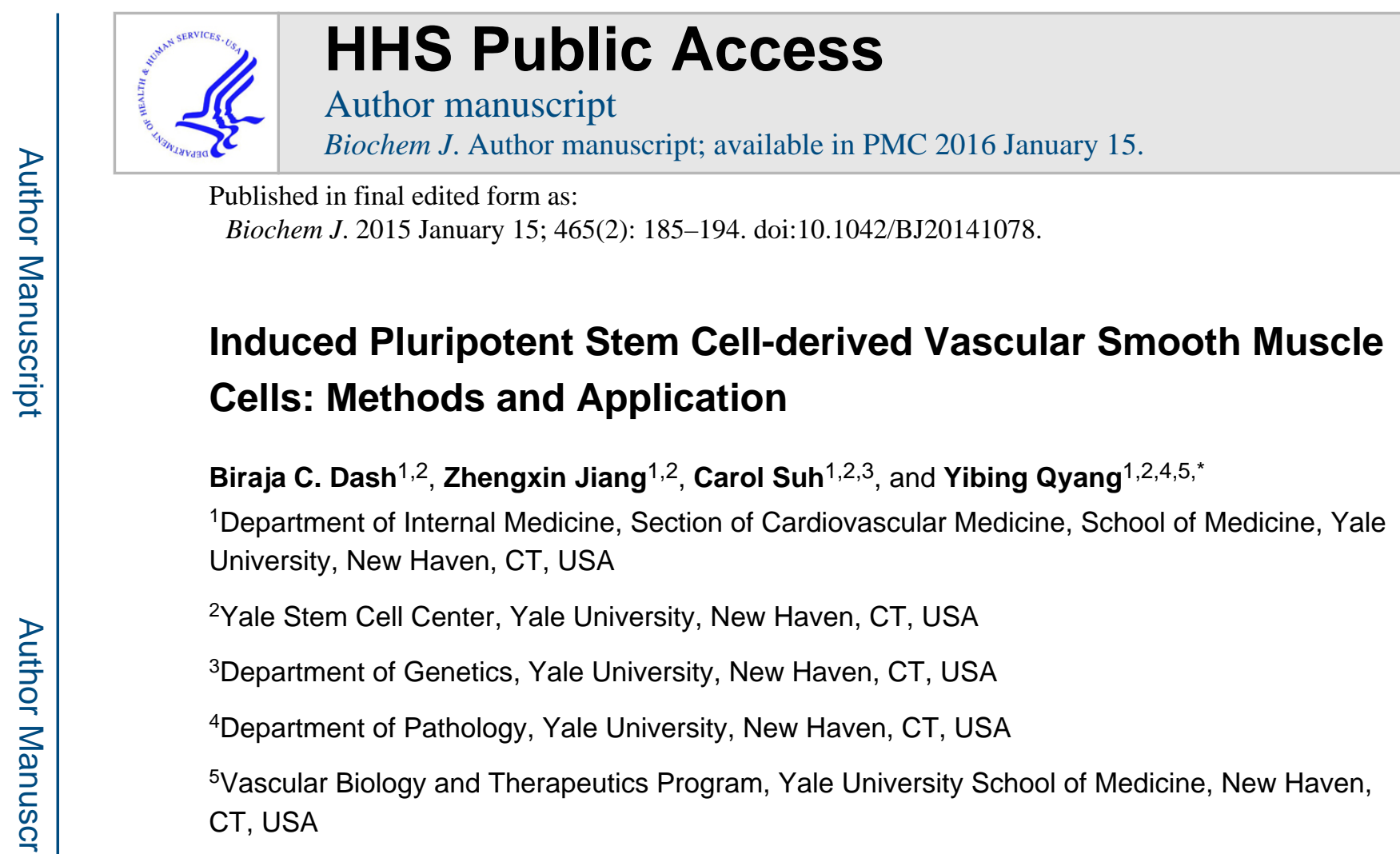

\begin{abstract}
Vascular smooth muscle cells (VSMCs) play a major role in the pathophysiology of cardiovascular diseases. The advent of induced pluripotent stem cell (iPSC) technology and their capability to differentiation into virtually every cell type in the human body make this field a ray of hope for vascular regenerative therapy and for understanding disease mechanism. In this review, we first discuss the recent iPSC technology and vascular smooth muscle development from embryo and then examine different methodology to derive VSMCs from iPSCs and their applications in regenerative therapy and disease modeling.
\end{abstract}

\title{
Introduction
}

The use of autologous cells is the benchmark for regenerative therapy in vascular diseases, which includes both local transplantation of the vascular cells to injured organs and the engineering of organs [1-3]. Vascular smooth muscle cells (VSMCs) with more than one developmental origin are crucial for cardiac and vascular function. VSMCs have recently been used for the treatment of cardiovascular diseases with limitations such as source and amount of the cells [4]. VSMCs proliferative potential decreases with increasing donor age and thus finding a reliable source of cells remains an important problem [4, 5]. The seminal finding by Shinya Yamanaka only 7 years ago that adult somatic adult cells could be reprogrammed into stem cells by the ectopic expression of factors, including Oct3/4, Sox 2 , Klf4 and c-Myc, has opened an exciting, new avenue for studying human disease and cellbased therapies [6]. These induced pluripotent stem cells (iPSCs) look and behave remarkably like embryonic stem cells and have the potential to differentiate into almost any somatic cell type. This technique has opened up new possibilities for the application of stem

"Corresponding Author: Dr. Yibing Qyang, Section of Cardiovascular Medicine, Department of Internal Medicine, Yale School of Medicine, Yale Stem Cell Center, New Haven, CT-06510, yibing.qyang@yale.edu. 
cells in the treatment of many diseases because there are minimal ethical problems with the availability of somatic cells. Thus, iPSCs represent an interesting alternative source for VSMC derivation compared to embryonic stem cells. Also, the use of patient-specific autologous cells minimizes transplantation and ethical problems. Importantly, iPSCs derived VSMCs can be used for vascular disease modeling studies as iPSCs derived from a patient will possess both the disease-causing mutation as well as the permissive genetic background that in many cases is required for full expression of the disease phenotype [7].

Different strategies have been used to make functional and contractile VSMCs using iPSCs and have been used for regenerative therapy and disease modeling in vascular medicine. The focus of this review is especially on recent advancements in iPSC technology, the diverse origin of VSMCs, and various methods to generate VSMCs from iPSCs and their potential use in regenerative therapy and disease modeling.

\section{Induced Pluripotent Stem Cell Technology}

Regenerative therapy by replacing damaged or diseased vascular tissue can be an exciting avenue to treat vascular diseases. The ability to generate a sufficient amount of VSMCs for cellular therapy was greatly enhanced upon the discovery of iPSCs. First developed in 2006 by Takahashi and Yamanaka, iPSCs are cells that retain the pluripotent properties of ESCs and are generated by reprogramming fibroblasts with the induction of Oct4, Klf4, Sox2, and c-Myc. [8-10]. In order for reprogramming to occur, fibroblast specific transcription factors need to be downregulated and proliferation needs to be induced following adoption of epithelial characteristics and ESC markers. Then pluripotency related genes are activated that allows the somatic cells to reach pluripotent states [11]. Since the initial discovery, many new technologies for iPSC derivation have been developed including deriving iPSCs from various somatic cell types including blood, which would allow for more feasible clinical application (Figure 1). The generation and use of iPSCs have become an attractive strategy for potential clinical applications such as disease modeling, cell-based therapy, and drug screening purposes due to their potential to differentiate into any cell type of interest [8-10].

The initial methods for iPSC generation required the use of retroviruses to deliver the reprogramming factors, but due to the risk of tumorigenesis and transgene reactivation, the emphasis shifted toward generating transgene-free iPSCs using transient adenoviral expression, episomal plasmids, and minicircle vectors [12-14]. Because these strategies utilize the transient and non-integrating nature of these vectors, the risk of tumorigenicity is greatly reduced compared to that of retro- or lentiviral vectors. However, the efficiency of generation using these techniques is extremely low and would need to be improved if used for clinical applications.

Other strategies to generate transgene-free iPSCs involve the expression of reprogramming factors that can then be excised, thus preventing reactivation of the transgenes. One method uses a single lentiviral cassette (STEMCCA) vector expressing the reprogramming factors, which can then be excised based on the Cre/loxP excision system [15]. An alternative excision approach uses piggyBac (PB) transposons, which involves transfecting somatic 
fibroblasts with doxycycline inducible transposon plasmids expressing c-Myc, Klf4, Oct4 and Sox 2 [12]. These strategies are advantageous because they exhibit higher efficiencies of reprogramming compared to that of the other transgene-free methods. Although the excision of the transgenes is highly efficient, there is still some concern of leaky excision, which would be a cause for concern for clinical grade use but can be improved upon. Another strategy that developed was the use of a Sendai virus, a non-integrating RNA virus, to deliver the reprogramming factors in a more practical and safer way [16-18].

As an alternative to vector based approaches, researchers have also developed protein-based and RNA based transgene free methods. In one method, recombinant forms of the reprogramming proteins were used to reprogram fibroblasts [19]. RNA based transgene free methods utilize the modification of mRNA to deliver non-integrating reprogramming factors and to prevent an immune response [20]. miRNAs were also used to induce pluripotency, which led to double the efficiency of reprogramming [21]. Improving the efficiency of iPSC generation would be useful for clinical applications where high numbers of VSMCs would be needed for cellular and tissue replacement therapies.

Recent methods of iPSC generation also include the use of small molecules to replace the delivery of reprogramming factors. For example, Pingping Hou et al. 2013 were able to identify a combination of seven small molecule compounds, such as Forskolin, 2-Me-5HT, and D4776, that facilitated reprogramming in mouse somatic cells with higher efficiency than previous methods [22]. Inducing reprogramming with small molecules instead of viral or vector-based methods would be an advantageous method for generating clinical grade iPSCs. Using this method would reduce the risk of transgene activation or genome integration and complications of the viral or vector based delivery methods for clinical grade manufacturing purposes because small molecules can be easily handled and delivered. The same group also discovered that there may be alternative ways to activate pluripotency by activation of lineage specifiers, such as GATA3, GATA6, and Sox7, which carefully manage the balance between differentiated and pluripotent states [23]. Based upon this "seesaw model" of balancing pluripotency factors and lineage specifiers, researchers may be able to find new ways of inducing pluripotency and improving the technology of iPSC generation.

Since the first generation of iPSCs, the field has advanced significantly regarding reprogramming efficiency and safety. Although viral vectors are still the most widely used method for reprogramming, it is not yet clear which protocol is the best method due to tradeoffs in efficiency and feasibility. In one study, Goh et al. 2013, compared the efficiency of reprogramming with different methods and found that the highest efficiency was achieved with mRNA based method (1.89\%), which was 20 fold higher than with the retroviral $(0.2 \%)$ and episomal plasmid $(0.10 \%)$ methods [24]. More systematic evaluation needs to be done to establish the best way of generating iPSCs. With new methods that allow for transgene-free iPSCs and further improvement of generation, iPSCs can become a powerful strategy for developing regenerative therapies for vascular diseases. 


\section{Origins of VSMCs during the mammalian cardiovascular development}

Early mammalian vascular development is regulated by endothelial cells (ECs), SMCs and pericytes. ECs form vascular plexus by angiogenesis to remodel and expand the vascular network, which subsequently attaches to the aorta and recruits mesenchymal cells to become VSMCs through arteriogenesis [25]. VSMCs provide contractile function and structural support to vascular blood vessels. In contrast to terminally differentiated cardiomyocytes in the cardiac system, differentiated VSMCs still retain considerable plasticity and can modify their phenotype in response to vessel injury [26]. VSMCs arise from multiple independent origins during development [7, 27]: most from various mesodermal lineages, a subset of them originates from the neural crest, the secondary heart field (SHF) and the proepicardial organ (PEO). Here, we provide a brief overview of the signaling pathways involved in the induction of VSMCs lining the walls of aorta and coronary arteries, which are crucial for continued heart growth and fetus survival towards birth.

The neuro-ectodermally derived neural crest cells, regulated by bone morphogenetic protein (BMP), Wnt, fibroblast growth factor (FGF), Notch and Retinoic acid (RA) signaling [28], are critical for the maturation of the functional arterial pole of the heart. Cardiac neural crest cells migrate through the pharyngeal arches and the anterior region of the SHF reaching the outflow tract (OFT) (Figure 2B), where they play a major role in the process of OFT remodeling [29]. The extensive remodeling results in the separation of the pulmonary trunk and aorta which connect with the right and left ventricles, respectively, ensuring blood flow to the lungs and body. Lineage tracing studies with neural crest specific Wnt1-cre and P0cre reporter mice provide evidence that cardiac neural crest cells give rise to VSMCs of the ascending aorta, the aortic arch and pulmonary trunk (Figure 2C, D) [29, 30]. However, cardiac neural crest derived SMCs are not found in the descending aorta nor at the aortic or pulmonary roots. Lineage tracing with Hoxb6-cre and Meox1-cre transgenic mice suggests that SMCs in the descending aorta derive from the somites rather than the lateral plate mesoderm [31] (Figure 2D). Multiple pathways, such as RA and Notch signaling, have been implicated in the differentiation of cardiac neural crest derived VSMCs. Proper balance of RA signaling and Tbx 1 expression controls both neural crest migration and VSMC differentiation, its deregulation leads to malformation of the pharyngeal arch arteries associated with the DiGeorge syndrome [32]. Studies of transgenic mice with inactivated Notch signaling in the neural crest derivatives show that Notch plays a cell-autonomous role in the differentiation of cardiac neural crest precursors into VSMCs, these mice exhibited aortic arch patterning defects, pulmonary artery stenosis, and ventricular septal defects [33, 34]. Furthermore, VSMC differentiation is impaired in pharyngeal neural crest derivatives of transgenic mice that either conditional gain or loss of Notch signaling in neural crest cells, this suggests that proper levels of Notch signaling is critical for neural crest derived VSMC differentiation [35]. Jagged1 is a direct target of Notch in smooth muscle and propagates SMC differentiation during aortic arch artery development. Loss of Jagged1 in neural crest impairs VSMC differentiation and leads to aortic arch artery defects [36].

The SHF arises from a medial population of progenitor cells along the anterior-posterior axis of the pharyngeal mesoderm behind the cardiac crescent [37], it constitutes a major source of cardiac progenitor cells as the primitive heart tube grows, and gives rise to the 
myocardium of the OFT and right ventricle [38]. In addition to providing myocardium to the arterial pole of the heart, Waldo et al demonstrate, using lineage tracer and VSMC markers, that SHF generates VSMCs at the base of the aorta and pulmonary trunk [39]. Similarly, cell fate analysis with the Tbx1 enhancer also confirms that VSMCs of the aortic/pulmonary roots originate from SHF-derived Tbx1-expressing cells [40] (Figure 2C, D).

VSMCs of the coronary arteries arise from the PEO and the epicardium (Figure 2). Proepicardial cells from the PEO, a transitory mesenchymal structure that forms at the posterior end of the heart tube (Figure 2B), migrate over the surface of the heart to form the epicardium [41] (Figure 2C). In response to myocardium derived signals, a subset of epicardial cells then enter the heart by epithelial to mesenchymal transformation (EMT), where they form early coronary vessels and give rise to coronary SMCs [42-44]. Lineage tracing studies suggest that the PEO originates from the lateral plate mesoderm progenitors that express Nkx2.5 and Is11 [45], providing evidence for a cross-talk of signals between the proepicardial and mesodermal lineages. Many signaling pathways that regulate epicardium, coronary vessel and coronary SMC development have been identified, such as Wnt, Sonic hedgehog (Shh), FGF, BMP, Notch and TGF- $\beta$ [46]. A proper balance of FGF and BMP signaling is crucial in determining the epicardial fate [47]. Shh acts as a downstream target of FGF during coronary vasculogenesis, inhibition of Shh signaling in the epicardium of the heart blocks coronary plexus formation [48]. Epicardial-specific deletion of $\beta$-catenin, a direct downstream target of the canonical Wnt signaling, leads to impaired epicardial EMT and loss of coronary arteries. This defect is caused by the lack of SMC recruitment, indicating that epicardial cells from $\beta$-catenin mutant embryos are unable to differentiate into SMCs [49]. Furthermore, Notch has been shown to regulate SMC differentiation in the epicardium, systemic and coronary vasculature through cooperation with TGF- $\beta 1[50,51]$.

Lineage tracing studies demonstrate that VSMCs from different embryonic origins have distinct functional properties. In chick embryos, TGF- $\beta 1$ promotes cell proliferation of neural crest derived SMCs with strong auto induction response, but inhibits the growth of paraxial mesoderm derived SMCs [52]. Similarly, Angiotensin II stimulates hyperplasia of the neuroectodermal SMCs, but gives rise to hypertrophy of the paraxial mesodermal SMCs [53]. Furthermore, studies in knockout mice show that neural crest derived SMCs require myocardin-related transcription factor B (MRTF-B) for differentiation, while paraxial mesodermal SMCs use myocardin $[54,55]$. The functional differences of multiple originspecific VSMC subtypes suggest that VSMC lineage diversity may give rise to distinct vascular diseases, and appropriate origin-specific VSMC subtype may be needed for optimal vascular graft therapies. Recently, multiple origin-specific VSMC subtypes from neuroectoderm, lateral plate mesoderm and paraxial mesoderm lineages have been generated using ESCs and iPSCs [56]. This seminal work will help in providing significant insights into the development of the vascular system and SMC related vascular disorders.

\section{Vascular Smooth Muscle Cells from iPSCs}

The potential use of iPSCs derived VSMCs in regenerative medicine may depend on efficient differentiation protocols (Figure 3). Various strategies that exist to induce in vitro differentiation of iPSCs to VSMCs are derived from ESCs differentiation protocol and could 
be categorized broadly into two culture methodologies: i) differentiation via embryoid bodies (EBs); ii) monolayer culture of iPSCs on extracellular matrix (ECM) coatings and by using of defined chemical conditions followed by culture manipulations [7, 57-60].

But before considering any method for differentiation of VSMCs from iPSCs, it is essential to carefully define the characteristic of VSMCs such as specific cellular markers and their functional characteristic such as their ability to modulate calcium transients and contract in response to agonists [7]. The cellular markers generally expressed by mature VSMCs include smooth muscle alpha actin, SM22a, calponin, smoothelin, and smooth muscle myosin heavy chain. And also they exhibit a well-defined fibrous morphology especially in mature VSMCs [7, 57].

\section{EB differentiation methods}

Differentiating via embryoid body method has an advantage of mimicking early embryonic development. Ge et al., differentiated VSMCs from human iPSCs generated from human fibroblast and VSMCs by following a protocol established by Xie et al. for hESCs [58, 61]. Briefly, in the first step human iPSCs were made into EBs and then cultured in suspension for 6 days in a differentiation medium containing Dulbecco modified Eagle medium supplemented with $10 \% \mathrm{FBS}, 1 \%$ nonessential amino acids, $0.1 \mathrm{mmol} / \mathrm{L} \beta$-mercaptoethanol and $1 \% \mathrm{~L}$-glutamine. The EBs were then plated on $0.1 \%$ gelatin-coated culture dishes and cultured with fresh differentiation medium. On day 6 the cells were dissociated and transferred to matrigel-coated plates in SmGM-2 media. After 1 week of culture on matrigel-coated plates, cells were again transferred to $0.1 \%$ gelatin-coated culture dishes and cultured with the 5\% FBS differentiation medium for at least 5 days to complete the differentiation. The VSMC like cells generated with this method showed calponin more than 95\% [58]. This method is the simplest EB approach to derive VSMCs in high purity without any need of FACS sorting. Thus, the cells derived have the potential to be used for disease modelling and tissue engineering applications. The potential limitation is that the VSMCs may have a mixed origin as the iPSCs were not induced into any specific lineage such as mesoderm, ectoderm or endoderm. Prior to this study, Lee et al., described a similar method but not that efficient one to differentiate iPSC into VSMCs [62]. In this method, unlike earlier one, colonies with VSMC-like cell morphology were manually picked and examined for the expression of VSMC-specific marker genes and positive cells were further expanded [62]. In this study, for the first time they derived iPSCs cells from human aortic vascular smooth muscle cells (HASMCs) and differentiated them back to VSMCs. Moreover, they observed that iPSC-derived cells have similar molecular and in vitro functional characteristics as those of HASMCs. This ground-breaking work further proved the use of iPSCs as an autologous cell source for patient-specific cell therapy.

Furthermore, a combination of two or more different methodologies was used to derive VSMCs [63]. In this method, Lin et al., reported making EBs out of human iPSCs and pretreated with a combination of growth factors VEGFA/dickkopf homologue 1 or VEGF/ bFGF on day 4. And by day 6 they were dissociated and sorted for multipotent cardiovascular progenitor cells (MCPs) with low KDR, c-kit-negative using flow cytometry. These MCPs were then cultured as a monolayer for 14 days using combination of growth 
factors either VEGF/DKK1 or VEGF/bFGF. The CD166 ${ }^{-}$and CD31- cells sorted from batch VEGF/DKK1 and VEGF/bFGF respectively were cultured with SMGM2 medium to generate VSMCs. Over $90 \%$ of $\mathrm{SMA}^{+}$cells were obtained from that of $\mathrm{CD} 166^{-}$and $\mathrm{CD} 31^{-}$ cell populations. Furthermore, these VSMCs showed similar contraction level to that of HASMC when treated with carbachol [63]. Also, using the same approach two populations of very important cardiovascular cells endothelial cells (ECs) and cardiomyocytes (CMs) were derived. The $\mathrm{CD} 166^{+}$and $\mathrm{CD} 31^{+}$cells were cardiomyocytes and endothelial cells respectively. Although this method needs FACS sorting to purify cardiovascular cells, the method is highly reproducible to derive simultaneously three different types of cardiovascular cells: ECs, VSMCs and CMs in high purity.

\section{Monolayer differentiation methods}

The EB method have been widely used for VSMC differentiation from hESCs and iPSCs with limitations such as: i) growth factors may only be effective for the cells on the exterior of EBs, ii) differentiation can be heterogeneous in EBs and iii) sorting by FACS reduces the viability of recovered cells. These limitations lead to development of methodologies for VSMC differentiation using monolayers of ECM proteins such as collagen IV and gelatin instead of EBs $[59,60]$. Human iPSCs were seeded at a concentration of $5 \times 10^{4} \mathrm{cells} / \mathrm{cm}^{2}$ onto plates previously coated with collagen IV. The hiPSCs were cultured for 6 days in a differentiation medium containing alpha-MEM, $10 \%$ FBS, and $0.1 \mathrm{mM} \beta$-mercaptoethanol. On Day 6, the differentiated cells were reseed on collagen IV coated plates at a concentration of $1.25 \times 10^{4}$ cells $/ \mathrm{cm}^{2}$ and supplemented with $10 \mathrm{ng} / \mathrm{mL}$ of platelet derived growth factor-BB (PDGF-BB) and $1 \mathrm{ng} / \mathrm{mL}$ TGF- $\beta 1$ for final VSMC differentiation with $98 \%$ of the cells positive for SMA, calponin, and SM22 and 50\% positive for SMMHC. The method described here can regulate the derivation of synthetic VSMCs and contractile VSMCs by changing the concentration of serum and growth factors PDGFBB and TGF $\beta$ in the differentiation medium. A high serum containing medium along with PDGFBB and TGF $\beta$ increased the production of synthetic VSMCs[60]. The synthetic VSMCs with increased production of ECM hold promise for application in the field of tissue engineering. On the other hand, medium without serum and PDGFBB helps in the synthesis of more contractile VSMCs with higher expression of SMMHC and elastin. The contractile VSMCs, when transplanted subcutaneously into nude mice, aligned themselves next to the host's growing functional vasculature, with occasional circumferential wrapping and vascular tube narrowing [60].

Another similar method used a partially induced pluripotent stem cells (PiPS) to generate VSMCs [59]. The human PiPS were seeded on collagen IV and cultured in differentiation media for four days to generate a population of finally differentiated PiPS-SMCs with $42.5 \%$ for calponin and 38\% for SM22. The PiPS-SMCs showed a full panel of SMCspecific markers most importantly SMA, calponin and SM22 both at the mRNA and protein level. Furthermore, PiPS-SMCs showed increased levels of elastin and collagen IA1 and contracted with response to $\mathrm{KCl}$. A mechanistic study performed on the differentiated cells showed the role of dickkopf 3 gene on PiPS-SMC differentiation by transcriptionally regulating SM22 by potentiation of Wnt signaling and interaction with Kremen1 [59]. This method requires a significantly shorter duration from reprogramming to SMC generation 
compared to that of iPSCs and their differentiation into VSMCs. In addition, unlike iPSCs, PiPS are not tumorigenic as they are derived by using a non-integrative method of overexpression of the four reprogramming factors. Furthermore, pure populations of PiPS can be obtained by a selection procedure. Thus, this method is a faster and simpler way to produce VSMCs for regenerative cell therapy.

Intermediate or transient cell populations like neural crest cells, cardiac progenitor cells and mesenchymal stem cells (MSCs) have been essential in differentiating VSMCs from human iPSCs. Menendez et al., showed that they can efficiently derive multipotent neural crest stem cells (NCSCs) from human pluripotent stem cells in a chemically defined media and using small molecules [64, 65]. By manipulating Wnt signaling and a Smad pathway they directed the differentiation of human pluripotent stem cells to multipotent neural crest cells. Furthermore, MSCs can be derived from these NCSCs and which in turn were differentiated to VSMCs among others cells such as melanocytes, peripheral neurons, bone, cartilage and fat cells $[64,65]$. The method described here is highly efficient and cost effective one-step direct differentiation of hiPSCs to NCSCs. The protocol helps in achieving pure population of NCSCs without any need of cell sorting. Furthermore, a large scale derivation of NCSCs can be achieved using this method. Thus, this method is a great tool for tissue engineering and regenerative medicine applications.

Similar to NCSCs cardiovascular progenitor cells (CVPCs) derived from human pluripotent stem cells, including hESCs and human iPSCs hold great promise for derivation of SMCs. Cao et al., have developed a fastest and most efficient method so far to produce an early population of CVPCs from hiPSCs using a chemically defined systems containing bone morphogenetic protein 4 (BMP4), glycogen synthase kinase 3 (GSK3) inhibitor CHIR99021 and ascorbic acid [66]. The methodology works by modulating the key early developmental pathways involved in human cardiovascular specification and CVPC self-renewal. The CVPCs when stimulated with $10 \mathrm{ng} / \mathrm{ml}$ PDGF-BB and $2 \mathrm{ng} / \mathrm{ml} \mathrm{TGF-} \beta 1$ for 12 days, they differentiate into VSMCs. The differentiated VSMCs showed phenotype similar to HASMC and expressed SMC specific markers such as a-SMA and SM-MHC. FACS sorting showed 96.7\% of cell population with a-SMA [66]. Furthermore, the CVPCs have the ability to differentiate into other cardiovascular cells such as CMs and ECs in high purity. The CVPCs generated are non-tumorigenic and have the potential to expand for long term. This long term expansion of these CVPCs is the most desirable trait for use in regenerative medicine.

A multistage and robust 2D differentiation protocol of VSMC was developed using MSCs as the intermediate cells [67]. The VSMCs were generated from human iPSC via an intermediate stage of MSCs by using soluble signals and extracellular matrix molecules. The MSCs were highly proliferative and expressed VSMC-related genes such as aSMA, CNN1, CALD1, SM22. The MSCs when treated with a combination of TGF $\beta 1(10 \mathrm{ng} / \mathrm{mL})$ and heparin $(30 \mathrm{mg} / \mathrm{mL})$ for 5 days. The combination TGF $\beta 1 /$ heparin treatment showed the highest expression of the late VSMC differentiation marker, myosin heavy chain along with aSMA, calponin, and caldesmon. This multistage strategy of differentiation from hiPSC to MSCs and MSCs to VSMCs allowed for expansion of an intermediate cell population, before induction of terminal differentiation into the contractile VSMCs [67]. 
Another such protocol where human iPSC-MSCs were used to derive VSMCs was by Zhang et al. [68]. They cultured iPSC-SMCs in EGM-2 medium with sphingosylphosphorylcholine $(5 \mathrm{mM})$ and TGF $\beta 1(2 \mathrm{ng} / \mathrm{ml})$ for 3 weeks. $50 \%-60 \%$ of the differentiated cell population expressed aSMA, calponin 1, and SMMH. They also displayed spindle-like morphology and showed contraction with the treatment of carbachol [68].

$\mathrm{CD} 4^{+}$progenitor cells are also potential source of VSMCs. Park et al have shown a promising method to efficiently produce $\mathrm{CD} 34$ positive progenitor cells from human iPSCs by combined modulation of two signaling pathways: mitogen-activated protein kinase (MAPK) extracellular signal-regulated protein kinase (MEK)/extracellular signal-regulated kinase (ERK) signaling and bone morphogenic protein-4 (BMP4) signaling [69]. The multistage protocol first derive cells of mesoderm lineage by treating hiPSCs with PD98059 (an inhibitor of MEK/ERK pathway) and BMP4. These cell populations were further treated with VEGF-A and bFGF for 6 days to derive CD $34^{+}$cells. $20 \%$ or more of the cell population are $\mathrm{CD} 34$ positive. The hiPSC-derived $\mathrm{CD} 34^{+}$cells when cultured in in EGM-2 medium supplemented with PDGFBB and bFGF for 15 to 21 days, they were differentiated to VSMCs with spindle-like morphologies and expressed aSMA and calponin. The functional assay using carbachol showed contraction of these cells [69]. Moreover, when these cells were implanted in ischemic mouse hind limbs, they helped in enhanced blood perfusion and limb salvage.

There are limited studies so far that show lineage specific derivation of VSMCs [7]. Recently Cheung et al., described a protocol to differentiate human pluripotent stem cells into developmental origin-specific SMC subtypes from neuroectoderm, lateral plate mesoderm and paraxial mesoderm lineages [56]. These intermediate cell populations were derived using a chemically define medium and specific factors contributing towards lineage specification. Neuroectoderm cell populations were derived from hiPSCs by culturing in a chemically defined medium supplemented with SB431542 (10 $\mu \mathrm{M})+$ FGF2 $(12 \mathrm{ng} / \mathrm{ml})$ for 7 days. Lateral plate and paraxial mesoderm lineages were derived from early mesoderm using a CDM/FGF2/BMP4 and CDM/FGF2/LY294002 respectively. These intermediate populations were further differentiated toward VSMCs in CDM+PDGF-BB $(10 \mathrm{ng} / \mathrm{ml})+$ TGF- $\beta 1(2 \mathrm{ng} / \mathrm{ml})$ for at least 12 days. The VSMCs coexpressed more than $80 \%$ myosin heavy chain 11 and aSMA. They also exhibited contractile ability when treated with carbachol and angiotensin II and helped in blood vessel formation in vivo. Moreover, the different SMC subtypes derived using this method showed SMC fate commitments and responded uniquely when exposed to cytokines. The method showed the ability to produce large scale of SMC subtypes which can be used in applications such as disease modeling with the appropriate origin-specific SMCs generated from patient-derived iPSCs and patient-matched SMCs for the construction of TEBVs. [56].

\section{VSMC Disease Modeling using iPSCs}

The major challenges in studying pathophysiology are: 1) difficulty in obtaining human patient tissue sample; 2) surgical specimens usually obtained represent end-stage disease, making it difficult to identify the initiators of disease or to delineate cause and effect; 3) use of genetically modified mouse models help to some extent with limitations such as species- 
specific differences in metabolic and biochemical activity, and underlying differences in chromosomal and genomic organization; and 4) especially many vascular diseases have a characteristic distribution or location despite systemic risk factors such as hypertension, lipid levels, or diabetes, which has in the main been attributed to anatomical and hemodynamic factors [7].

Vascular SMCs play a key role in vascular disease and because they have diverse embryonic origin, hiPSC-SMCs will have potential in using for disease modeling as patient derived iPSCs, when modeling genetic diseases is that the resultant VSMCs not only contain the disease causing mutation but also have the permissive genetic background required in many cases for full expression of the disease [7, 58, 68]. Recently, we generated human hiPSC lines from patients with supravalvular aortic stenosis (SVAS) and Williams-Beuren syndrome (WBS). Vascular SMCs derived from these two iPSC lines were not mature enough with a fewer amount of organized networks of SMA filament bundles. Furthermore, these VSMCs showed higher proliferation rate compared to control iPSC-SMCs. The diseased phenotype of VSMCs from both the iPSC lines was rescued either by adding recombinant elastin protein or enhancing of small GTPase RhoA signaling. Another Study was on Hutchinson-Gilford progeria (HGP) syndrome [68]. HGP syndrome is caused by a Lamin A mutation, which leads to accumulation of the mutant protein progerin and which in turn increased DNA damage. HGP iPSCs, were used to derive VSMCs among other cells and found to be among the most severely affected cell types [68]. Zhang et al., found progerin to bind to the DNA-dependent protein kinase catalytic subunit in the HGP iPSCSMCs, which reduced the nuclear holoenzyme and resulted in decreased SMC proliferation [68]. Although these two studies demonstrate how iPSC-based in vitro models may be used to generate new insights into the molecular mechanisms underlying their respective diseases, many aspects of the molecular pathology still need to be clarified in both of these conditions. Furthermore, in vitro disease models created using hiPSCs can significantly improve the never-ending search for new pharmacological cures by means of drug screening.

In conclusion, iPSC-derived VSMCs offer a unique and alternative system to study vascular disease in a human context than genetically modified animal models as well as an abundant source of VSMCs. Furthermore, it gives an opportunity possibly to study disease at the beginning rather than the later stages.

\section{Regenerative Therapy}

Transplantation of vascular cells has tremendous potential for vascular regeneration either by restoring blood flow to ischemic tissues or implanting a tissue engineered blood vessel [70, 71]. So far no clinical trials have been performed using these cells due to a concern for potential tumorigenicity abilities of these cells [72-74]. There are very few preclinical studies that have been reported so far using iPSC-SMCs. Hibino et al., made a cell sheet out of differentiated mouse iPS cells with mix a population of ECs and VSMCs [75]. The sheets were seeded onto a biodegradable scaffold composed of PGA-P (CL/LA) with a diameter of $0.8 \mathrm{~mm}$ and were implanted as interposition grafts in the inferior vena cava of female $\mathrm{SCID} / \mathrm{bg}$ mice. All mice survived without thrombosis, aneurysm formation, graft rupture or 
calcification. Histological evaluation of the grafts demonstrated endothelialization with VWF and an inner layer with SMA and calponin positive cells at 10 weeks [75].

Tissue engineered blood vessels (TEBVs) hold promise as tools for surgical replacement of the affected vessels in patients with peripheral arterial and coronary arterial diseases. One of the approaches is the use of autologous cells to generate these TEBVs [76-78]. The limitations of this approach are high production cost and most importantly long wait time of up to nine months. To circumvent these limitations allogeneic cells have been used to generate TEBVs [79, 80]. Dahl et al., described a method where they cultured allogeneic VSMCs obtained from cadaveric donors on rapidly degradable polyglycolic acid (PGA) tubular scaffolds to generate TEBVs within 2 months. TEBVs were then decellularised to remove antigenic, allogeneic cells from the graft, thereby allowing the use of stored allogeneic cells to produce TEBVs that are nonimmunogenic and can be used in any recipient [80]. iPSC technology has revolutionized the field of TEBVs by having the ability to produce patient specific VSMCs in large scale. Recently, Karamiriti et al., derived large scale VSMCs from PiPSCs in a shorter duration [59]. These PiPS-SMCs when seeded onto a decellularised vascular graft repopulated the graft and ultimately giving rise to a functional tissue-engineered vessels when combined with previously established PiPS-endothelial cells, leading to increased survival of severe combined immunodeficiency mice after transplantation of the vessel as a vascular graft [59].

Another study showed making a vascular graft using mouse iPSC-SMCs on threedimensional (3D) macro-porous nanofibrous (NF) poly(L-lactide) (PLLA) scaffolds in vitro. Upon subcutaneous implantation, the implanted cells maintained the VSMC phenotype [81]. Recently, we have generated TEBVs using hiPSC-SMCs (Unpublished). Briefly, the cells were seeded on PGA scaffolds and were cultured for 8 weeks in a static condition. The harvested blood vessels showed a very thick and homogeneous deposition of collagen matrix. The TEBV had enough strength to be implanted in a nude rat. Also, we have fabricated tissue engineered vascular rings using these hiPSC-SMCs (Unpublished). The hiPSC-SMC rings showed more universal tensile strength than the control primary SMCs derived rings. The rings when joined together in the future might form a tube and could further be optimized for implantation.

One of the concern before regenerative medicine using ESC- or iPSC-derived cells is the possible tumorigenic side effects of ESC- or iPSC-derived vascular progenitors. However, new technologies to generate 'integration-free' iPSCs may address these concerns to some degree. Also, a recent article showed another novel approach of overcoming tumor or teratoma formation induced by iPSCs [82]. They showed that treatment of hiPSC derived mixed population of cells with small molecules such as chemical inhibitors (quercetin or YM155) of antiapoptotic factor survivin could selectively eliminate undifferentiated iPSCs with teratoma or tumor forming potentiality [82].

\section{Conclusions}

iPSCs could be an unlimited source for VSMCs. This review has focused on the key steps of iPSC technology and VSMCs generation. We have attempted to describe the recent progress 
in different methods to derive VSMCs from iPSCs and so far their application for regenerative therapy and disease modeling. Improvement in both in vitro cell culture systems and in vivo translational studies to optimize the potential and function of iPSC derived VSMCs could enable translation from experimental and pre-clinical studies to human clinical therapies.

\section{Acknowledgments}

The author(s) acknowledge their financial supports for the research, authorship, and/or publication of this article: NIH 1K02HL101990-01 and 1R01HL116705-01, Connecticut Stem Cell Research Program 12-SCB-YALE-06, 11SCA33 and 11SCB18, AHA 09SDG2080420, Cardiovascular Medical Research and Education Fund and National Science Foundation Graduate Research Fellowship DGE-1122492. We also acknowledge and apologize to colleagues whose studies were not included for discussion in this review due to space limitation.

\section{References}

1. Fadini GP, Agostini C, Avogaro A. Autologous stem cell therapy for peripheral arterial disease meta-analysis and systematic review of the literature. Atherosclerosis. 2010; 209:10-17. [PubMed: 19740466]

2. Griese DP, Ehsan A, Melo LG, Kong D, Zhang L, Mann MJ, Pratt RE, Mulligan RC, Dzau VJ. Isolation and transplantation of autologous circulating endothelial cells into denuded vessels and prosthetic grafts: implications for cell-based vascular therapy. Circulation. 2003; 108:2710-2715. [PubMed: 14597586]

3. Nakagami H, Maeda K, Morishita R, Iguchi S, Nishikawa T, Takami Y, Kikuchi Y, Saito Y, Tamai K, Ogihara T, Kaneda Y. Novel autologous cell therapy in ischemic limb disease through growth factor secretion by cultured adipose tissue-derived stromal cells. Arterioscler Thromb Vasc Biol. 2005; 25:2542-2547. [PubMed: 16224047]

4. Li RK, Jia ZQ, Weisel RD, Merante F, Mickle DA. Smooth muscle cell transplantation into myocardial scar tissue improves heart function. Journal of molecular and cellular cardiology. 1999; 31:513-522. [PubMed: 10198183]

5. Owens GK, Vernon SM, Madsen CS. Molecular regulation of smooth muscle cell differentiation. Journal of hypertension. Supplement: official journal of the International Society of Hypertension. 1996; 14:S55-64. [PubMed: 9120686]

6. Takahashi K, Yamanaka S. Induction of pluripotent stem cells from mouse embryonic and adult fibroblast cultures by defined factors. Cell. 2006; 126:663-676. [PubMed: 16904174]

7. Sinha S, Iyer D, Granata A. Embryonic origins of human vascular smooth muscle cells: implications for in vitro modeling and clinical application. Cellular and molecular life sciences: CMLS. 2014

8. Takahashi K, Tanabe K, Ohnuki M, Narita M, Ichisaka T, Tomoda K, Yamanaka S. Induction of pluripotent stem cells from adult human fibroblasts by defined factors. Cell. 2007; 131:861-872. [PubMed: 18035408]

9. Yu J, Vodyanik MA, Smuga-Otto K, Antosiewicz-Bourget J, Frane JL, Tian S, Nie J, Jonsdottir GA, Ruotti V, Stewart R, Slukvin II, Thomson JA. Induced pluripotent stem cell lines derived from human somatic cells. Science. 2007; 318:1917-1920. [PubMed: 18029452]

10. Park IH, Zhao R, West JA, Yabuuchi A, Huo H, Ince TA, Lerou PH, Lensch MW, Daley GQ. Reprogramming of human somatic cells to pluripotency with defined factors. Nature. 2008; 451:141-146. [PubMed: 18157115]

11. Plath K, Lowry WE. Progress in understanding reprogramming to the induced pluripotent state. Nat Rev Genet. 2011; 12:253-265. [PubMed: 21415849]

12. Woltjen K, Michael IP, Mohseni P, Desai R, Mileikovsky M, Hamalainen R, Cowling R, Wang W, Liu P, Gertsenstein M, Kaji K, Sung HK, Nagy A. piggyBac transposition reprograms fibroblasts to induced pluripotent stem cells. Nature. 2009; 458:766-770. [PubMed: 19252478]

13. Yu J, Hu K, Smuga-Otto K, Tian S, Stewart R, Slukvin II, Thomson JA. Human induced pluripotent stem cells free of vector and transgene sequences. Science. 2009; 324:797-801. [PubMed: 19325077] 
14. Jia F, Wilson KD, Sun N, Gupta DM, Huang M, Li Z, Panetta NJ, Chen ZY, Robbins RC, Kay MA, Longaker MT, Wu JC. A nonviral minicircle vector for deriving human iPS cells. Nature methods. 2010; 7:197-199. [PubMed: 20139967]

15. Sommer CA, Sommer AG, Longmire TA, Christodoulou C, Thomas DD, Gostissa M, Alt FW, Murphy GJ, Kotton DN, Mostoslavsky G. Excision of reprogramming transgenes improves the differentiation potential of iPS cells generated with a single excisable vector. Stem Cells. 2010; 28:64-74. [PubMed: 19904830]

16. Fusaki N, Ban H, Nishiyama A, Saeki K, Hasegawa M. Efficient induction of transgene-free human pluripotent stem cells using a vector based on Sendai virus, an RNA virus that does not integrate into the host genome. Proceedings of the Japan Academy. Series B, Physical and biological sciences. 2009; 85:348-362.

17. Seki T, Yuasa S, Oda M, Egashira T, Yae K, Kusumoto D, Nakata H, Tohyama S, Hashimoto H, Kodaira M, Okada Y, Seimiya H, Fusaki N, Hasegawa M, Fukuda K. Generation of induced pluripotent stem cells from human terminally differentiated circulating T cells. Cell Stem Cell. 2010; 7:11-14. [PubMed: 20621043]

18. Ban H, Nishishita N, Fusaki N, Tabata T, Saeki K, Shikamura M, Takada N, Inoue M, Hasegawa M, Kawamata S, Nishikawa S. Efficient generation of transgene-free human induced pluripotent stem cells (iPSCs) by temperature-sensitive Sendai virus vectors. Proc Natl Acad Sci U S A. 2011; 108:14234-14239. [PubMed: 21821793]

19. Zhou H, Wu S, Joo JY, Zhu S, Han DW, Lin T, Trauger S, Bien G, Yao S, Zhu Y, Siuzdak G, Scholer HR, Duan L, Ding S. Generation of induced pluripotent stem cells using recombinant proteins. Cell Stem Cell. 2009; 4:381-384. [PubMed: 19398399]

20. Warren L, Manos PD, Ahfeldt T, Loh YH, Li H, Lau F, Ebina W, Mandal PK, Smith ZD, Meissner A, Daley GQ, Brack AS, Collins JJ, Cowan C, Schlaeger TM, Rossi DJ. Highly efficient reprogramming to pluripotency and directed differentiation of human cells with synthetic modified mRNA. Cell Stem Cell. 2010; 7:618-630. [PubMed: 20888316]

21. Anokye-Danso F, Trivedi CM, Juhr D, Gupta M, Cui Z, Tian Y, Zhang Y, Yang W, Gruber PJ, Epstein JA, Morrisey EE. Highly efficient miRNA-mediated reprogramming of mouse and human somatic cells to pluripotency. Cell Stem Cell. 2011; 8:376-388. [PubMed: 21474102]

22. Hou P, Li Y, Zhang X, Liu C, Guan J, Li H, Zhao T, Ye J, Yang W, Liu K, Ge J, Xu J, Zhang Q, Zhao Y, Deng H. Pluripotent stem cells induced from mouse somatic cells by small-molecule compounds. Science. 2013; 341:651-654. [PubMed: 23868920]

23. Shu J, Wu C, Wu Y, Li Z, Shao S, Zhao W, Tang X, Yang H, Shen L, Zuo X, Yang W, Shi Y, Chi X, Zhang H, Gao G, Shu Y, Yuan K, He W, Tang C, Zhao Y, Deng H. Induction of pluripotency in mouse somatic cells with lineage specifiers. Cell. 2013; 153:963-975. [PubMed: 23706735]

24. Goh PA, Caxaria S, Casper C, Rosales C, Warner TT, Coffey PJ, Nathwani AC. A systematic evaluation of integration free reprogramming methods for deriving clinically relevant patient specific induced pluripotent stem (iPS) cells. PloS one. 2013; 8:e81622. [PubMed: 24303062]

25. Jain RK. Molecular regulation of vessel maturation. Nature medicine. 2003; 9:685-693.

26. Spin JM, Maegdefessel L, Tsao PS. Vascular smooth muscle cell phenotypic plasticity: focus on chromatin remodelling. Cardiovascular research. 2012; 95:147-155. [PubMed: 22362814]

27. Majesky MW. Developmental basis of vascular smooth muscle diversity. Arteriosclerosis, thrombosis, and vascular biology. 2007; 27:1248-1258.

28. Villanueva S, Glavic A, Ruiz P, Mayor R. Posteriorization by FGF, Wnt, and retinoic acid is required for neural crest induction. Developmental biology. 2002; 241:289-301. [PubMed: 11784112]

29. Jiang X, Rowitch DH, Soriano P, McMahon AP, Sucov HM. Fate of the mammalian cardiac neural crest. Development (Cambridge, England). 2000; 127:1607-1616.

30. Nakamura T, Colbert MC, Robbins J. Neural crest cells retain multipotential characteristics in the developing valves and label the cardiac conduction system. Circulation research. 2006; 98:15471554. [PubMed: 16709902]

31. Wasteson P, Johansson BR, Jukkola T, Breuer S, Akyurek LM, Partanen J, Lindahl P. Developmental origin of smooth muscle cells in the descending aorta in mice. Development (Cambridge, England). 2008; 135:1823-1832. 
32. Ryckebusch L, Bertrand N, Mesbah K, Bajolle F, Niederreither K, Kelly RG, Zaffran S. Decreased levels of embryonic retinoic acid synthesis accelerate recovery from arterial growth delay in a mouse model of DiGeorge syndrome. Circulation research. 2010; 106:686-694. [PubMed: 20110535]

33. High FA, Zhang M, Proweller A, Tu L, Parmacek MS, Pear WS, Epstein JA. An essential role for Notch in neural crest during cardiovascular development and smooth muscle differentiation. The Journal of clinical investigation. 2007; 117:353-363. [PubMed: 17273555]

34. Varadkar P, Kraman M, Despres D, Ma G, Lozier J, McCright B. Notch2 is required for the proliferation of cardiac neural crest-derived smooth muscle cells. Developmental dynamics: an official publication of the American Association of Anatomists. 2008; 237:1144-1152. [PubMed: 18330927]

35. Mead TJ, Yutzey KE. Notch pathway regulation of neural crest cell development in vivo. Developmental dynamics: an official publication of the American Association of Anatomists. 2012; 241:376-389. [PubMed: 22275227]

36. Manderfield LJ, High FA, Engleka KA, Liu F, Li L, Rentschler S, Epstein JA. Notch activation of Jagged 1 contributes to the assembly of the arterial wall. Circulation. 2012; 125:314-323. [PubMed: 22147907]

37. Buckingham M, Meilhac S, Zaffran S. Building the mammalian heart from two sources of myocardial cells. Nature reviews. Genetics. 2005; 6:826-835.

38. Kelly RG, Brown NA, Buckingham ME. The arterial pole of the mouse heart forms from Fgf10expressing cells in pharyngeal mesoderm. Developmental cell. 2001; 1:435-440. [PubMed: 11702954]

39. Waldo KL, Hutson MR, Ward CC, Zdanowicz M, Stadt HA, Kumiski D, Abu-Issa R, Kirby ML. Secondary heart field contributes myocardium and smooth muscle to the arterial pole of the developing heart. Developmental biology. 2005; 281:78-90. [PubMed: 15848390]

40. Maeda J, Yamagishi H, McAnally J, Yamagishi C, Srivastava D. Tbx1 is regulated by forkhead proteins in the secondary heart field. Developmental dynamics: an official publication of the American Association of Anatomists. 2006; 235:701-710. [PubMed: 16444712]

41. Manner J, Perez-Pomares JM, Macias D, Munoz-Chapuli R. The origin, formation and developmental significance of the epicardium: a review. Cells, tissues, organs. 2001; 169:89-103. [PubMed: 11399849]

42. Landerholm TE, Dong XR, Lu J, Belaguli NS, Schwartz RJ, Majesky MW. A role for serum response factor in coronary smooth muscle differentiation from proepicardial cells. Development (Cambridge, England). 1999; 126:2053-2062.

43. Lu J, Landerholm TE, Wei JS, Dong XR, Wu SP, Liu X, Nagata K, Inagaki M, Majesky MW. Coronary smooth muscle differentiation from proepicardial cells requires rhoA-mediated actin reorganization and p160 rho-kinase activity. Developmental biology. 2001; 240:404-418. [PubMed: 11784072]

44. Mikawa T, Gourdie RG. Pericardial mesoderm generates a population of coronary smooth muscle cells migrating into the heart along with ingrowth of the epicardial organ. Developmental biology. 1996; 174:221-232. [PubMed: 8631495]

45. Zhou B, von Gise A, Ma Q, Rivera-Feliciano J, Pu WT. Nkx2-5- and Isl1-expressing cardiac progenitors contribute to proepicardium. Biochemical and biophysical research communications. 2008; 375:450-453. [PubMed: 18722343]

46. Perez-Pomares JM, de la Pompa JL. Signaling during epicardium and coronary vessel development. Circulation research. 2011; 109:1429-1442. [PubMed: 22158650]

47. Kruithof BP, van Wijk B, Somi S, Kruithof-de Julio M, Perez Pomares JM, Weesie F, Wessels A, Moorman AF, van den Hoff MJ. BMP and FGF regulate the differentiation of multipotential pericardial mesoderm into the myocardial or epicardial lineage. Developmental biology. 2006; 295:507-522. [PubMed: 16753139]

48. Lavine KJ, Long F, Choi K, Smith C, Ornitz DM. Hedgehog signaling to distinct cell types differentially regulates coronary artery and vein development. Development (Cambridge, England). 2008; 135:3161-3171. 
49. Zamora M, Manner J, Ruiz-Lozano P. Epicardium-derived progenitor cells require beta-catenin for coronary artery formation. Proceedings of the National Academy of Sciences of the United States of America. 2007; 104:18109-18114. [PubMed: 17989236]

50. Grieskamp T, Rudat C, Ludtke TH, Norden J, Kispert A. Notch signaling regulates smooth muscle differentiation of epicardium-derived cells. Circulation research. 2011; 108:813-823. [PubMed: 21252157]

51. Tang Y, Urs S, Boucher J, Bernaiche T, Venkatesh D, Spicer DB, Vary CP, Liaw L. Notch and transforming growth factor-beta (TGFbeta) signaling pathways cooperatively regulate vascular smooth muscle cell differentiation. The Journal of biological chemistry. 2010; 285:17556-17563. [PubMed: 20368328]

52. Topouzis S, Majesky MW. Smooth Muscle Lineage Diversity in the Chick Embryo. Developmental biology. 1996; 178:430-445.

53. Owens AP 3rd, Subramanian V, Moorleghen JJ, Guo Z, McNamara CA, Cassis LA, Daugherty A. Angiotensin II induces a region-specific hyperplasia of the ascending aorta through regulation of inhibitor of differentiation 3. Circulation research. 2010; 106:611-619. [PubMed: 20019328]

54. Li J, Zhu X, Chen M, Cheng L, Zhou D, Lu MM, Du K, Epstein JA, Parmacek MS. Myocardinrelated transcription factor $\mathrm{B}$ is required in cardiac neural crest for smooth muscle differentiation and cardiovascular development. Proceedings of the National Academy of Sciences of the United States of America. 2005; 102:8916-8921. [PubMed: 15951419]

55. Oh J, Richardson JA, Olson EN. Requirement of myocardin-related transcription factor-B for remodeling of branchial arch arteries and smooth muscle differentiation. Proceedings of the National Academy of Sciences of the United States of America. 2005; 102:15122-15127. [PubMed: 16204380]

56. Cheung C, Bernardo AS, Trotter MW, Pedersen RA, Sinha S. Generation of human vascular smooth muscle subtypes provides insight into embryological origin-dependent disease susceptibility. Nat Biotechnol. 2012; 30:165-173. [PubMed: 22252507]

57. Descamps B, Emanueli C. Vascular differentiation from embryonic stem cells: novel technologies and therapeutic promises. Vascular pharmacology. 2012; 56:267-279. [PubMed: 22504071]

58. Ge X, Ren Y, Bartulos O, Lee MY, Yue Z, Kim KY, Li W, Amos PJ, Bozkulak EC, Iyer A, Zheng W, Zhao H, Martin KA, Kotton DN, Tellides G, Park IH, Yue L, Qyang Y. Modeling supravalvular aortic stenosis syndrome with human induced pluripotent stem cells. Circulation. 2012; 126:1695-1704. [PubMed: 22914687]

59. Karamariti E, Margariti A, Winkler B, Wang X, Hong X, Baban D, Ragoussis J, Huang Y, Han JD, Wong MM, Sag CM, Shah AM, Hu Y, Xu Q. Smooth muscle cells differentiated from reprogrammed embryonic lung fibroblasts through DKK3 signaling are potent for tissue engineering of vascular grafts. Circ Res. 2013; 112:1433-1443. [PubMed: 23529184]

60. Wanjare M, Kuo F, Gerecht S. Derivation and maturation of synthetic and contractile vascular smooth muscle cells from human pluripotent stem cells. Cardiovasc Res. 2013; 97:321-330. [PubMed: 23060134]

61. Xie CQ, Zhang J, Villacorta L, Cui T, Huang H, Chen YE. A highly efficient method to differentiate smooth muscle cells from human embryonic stem cells. Arterioscler Thromb Vasc Biol. 2007; 27:e311-312. [PubMed: 18029907]

62. Lee TH, Song SH, Kim KL, Yi JY, Shin GH, Kim JY, Kim J, Han YM, Lee SH, Lee SH, Shim $\mathrm{SH}$, Suh W. Functional recapitulation of smooth muscle cells via induced pluripotent stem cells from human aortic smooth muscle cells. Circ Res. 2010; 106:120-128. [PubMed: 19959777]

63. Lin B, Kim J, Li Y, Pan H, Carvajal-Vergara X, Salama G, Cheng T, Li Y, Lo CW, Yang L. Highpurity enrichment of functional cardiovascular cells from human iPS cells. Cardiovasc Res. 2012; 95:327-335. [PubMed: 22673369]

64. Menendez L, Kulik MJ, Page AT, Park SS, Lauderdale JD, Cunningham ML, Dalton S. Directed differentiation of human pluripotent cells to neural crest stem cells. Nat Protoc. 2013; 8:203-212. [PubMed: 23288320]

65. Menendez L, Yatskievych TA, Antin PB, Dalton S. Wnt signaling and a Smad pathway blockade direct the differentiation of human pluripotent stem cells to multipotent neural crest cells. Proc Natl Acad Sci U S A. 2011; 108:19240-19245. [PubMed: 22084120] 
66. Cao N, Liang H, Huang J, Wang J, Chen Y, Chen Z, Yang HT. Highly efficient induction and long-term maintenance of multipotent cardiovascular progenitors from human pluripotent stem cells under defined conditions. Cell Res. 2013; 23:1119-1132. [PubMed: 23896987]

67. Bajpai VK, Mistriotis P, Loh YH, Daley GQ, Andreadis ST. Functional vascular smooth muscle cells derived from human induced pluripotent stem cells via mesenchymal stem cell intermediates. Cardiovasc Res. 2012; 96:391-400. [PubMed: 22941255]

68. Zhang J, Lian Q, Zhu G, Zhou F, Sui L, Tan C, Mutalif RA, Navasankari R, Zhang Y, Tse HF, Stewart CL, Colman A. A human iPSC model of Hutchinson Gilford Progeria reveals vascular smooth muscle and mesenchymal stem cell defects. Cell Stem Cell. 2011; 8:31-45. [PubMed: 21185252]

69. Park SW, Jun Koh Y, Jeon J, Cho YH, Jang MJ, Kang Y, Kim MJ, Choi C, Sook Cho Y, Chung HM, Koh GY, Han YM. Efficient differentiation of human pluripotent stem cells into functional CD34+ progenitor cells by combined modulation of the MEK/ERK and BMP4 signaling pathways. Blood. 2010; 116:5762-5772. [PubMed: 20884805]

70. Lee AY, Mahler N, Best C, Lee YU, Breuer CK. Regenerative implants for cardiovascular tissue engineering. Translational research: the journal of laboratory and clinical medicine. 2014; 163:321-341. [PubMed: 24589506]

71. Stamm C, Klose K, Choi YH. Clinical application of stem cells in the cardiovascular system. Advances in biochemical engineering/biotechnology. 2010; 123:293-317. [PubMed: 20803146]

72. Lu X, Zhao T. Clinical therapy using iPSCs: hopes and challenges. Genomics, proteomics \& bioinformatics. 2013; 11:294-298.

73. Okano H, Nakamura M, Yoshida K, Okada Y, Tsuji O, Nori S, Ikeda E, Yamanaka S, Miura K. Steps toward safe cell therapy using induced pluripotent stem cells. Circ Res. 2013; 112:523-533. [PubMed: 23371901]

74. Kuroda T, Yasuda S, Sato Y. Tumorigenicity studies for human pluripotent stem cell-derived products. Biological \& pharmaceutical bulletin. 2013; 36:189-192. [PubMed: 23370350]

75. Hibino N, Duncan DR, Nalbandian A, Yi T, Qyang Y, Shinoka T, Breuer CK. Evaluation of the use of an induced puripotent stem cell sheet for the construction of tissue-engineered vascular grafts. The Journal of thoracic and cardiovascular surgery. 2012; 143:696-703. [PubMed: 22244569]

76. Shin'oka T, Matsumura G, Hibino N, Naito Y, Watanabe M, Konuma T, Sakamoto T, Nagatsu M, Kurosawa H. Midterm clinical result of tissue-engineered vascular autografts seeded with autologous bone marrow cells. The Journal of thoracic and cardiovascular surgery. 2005; 129:1330-1338. [PubMed: 15942574]

77. McAllister TN, Dusserre N, Maruszewski M, L'Heureux N. Cell-based therapeutics from an economic perspective: primed for a commercial success or a research sinkhole? Regen Med. 2008; 3:925-937. [PubMed: 18947313]

78. McAllister TN, Maruszewski M, Garrido SA, Wystrychowski W, Dusserre N, Marini A, Zagalski K, Fiorillo A, Avila H, Manglano X, Antonelli J, Kocher A, Zembala M, Cierpka L, de la Fuente LM, L'Heureux N. Effectiveness of haemodialysis access with an autologous tissue-engineered vascular graft: a multicentre cohort study. Lancet. 2009; 373:1440-1446. [PubMed: 19394535]

79. Quint C, Arief M, Muto A, Dardik A, Niklason LE. Allogeneic human tissue-engineered blood vessel. J Vasc Surg. 2012; 55:790-798. [PubMed: 22056286]

80. Dahl SL, Kypson AP, Lawson JH, Blum JL, Strader JT, Li Y, Manson RJ, Tente WE, DiBernardo L, Hensley MT, Carter R, Williams TP, Prichard HL, Dey MS, Begelman KG, Niklason LE. Readily available tissue-engineered vascular grafts. Science translational medicine. 2011; 3:68ra69.

81. Xie C, Hu J, Ma H, Zhang J, Chang LJ, Chen YE, Ma PX. Three-dimensional growth of iPS cellderived smooth muscle cells on nanofibrous scaffolds. Biomaterials. 2011; 32:4369-4375. [PubMed: 21439638]

82. Lee MO, Moon SH, Jeong HC, Yi JY, Lee TH, Shim SH, Rhee YH, Lee SH, Oh SJ, Lee MY, Han MJ, Cho YS, Chung HM, Kim KS, Cha HJ. Inhibition of pluripotent stem cell-derived teratoma formation by small molecules. Proc Natl Acad Sci U S A. 2013; 110:E3281-3290. [PubMed: 23918355] 


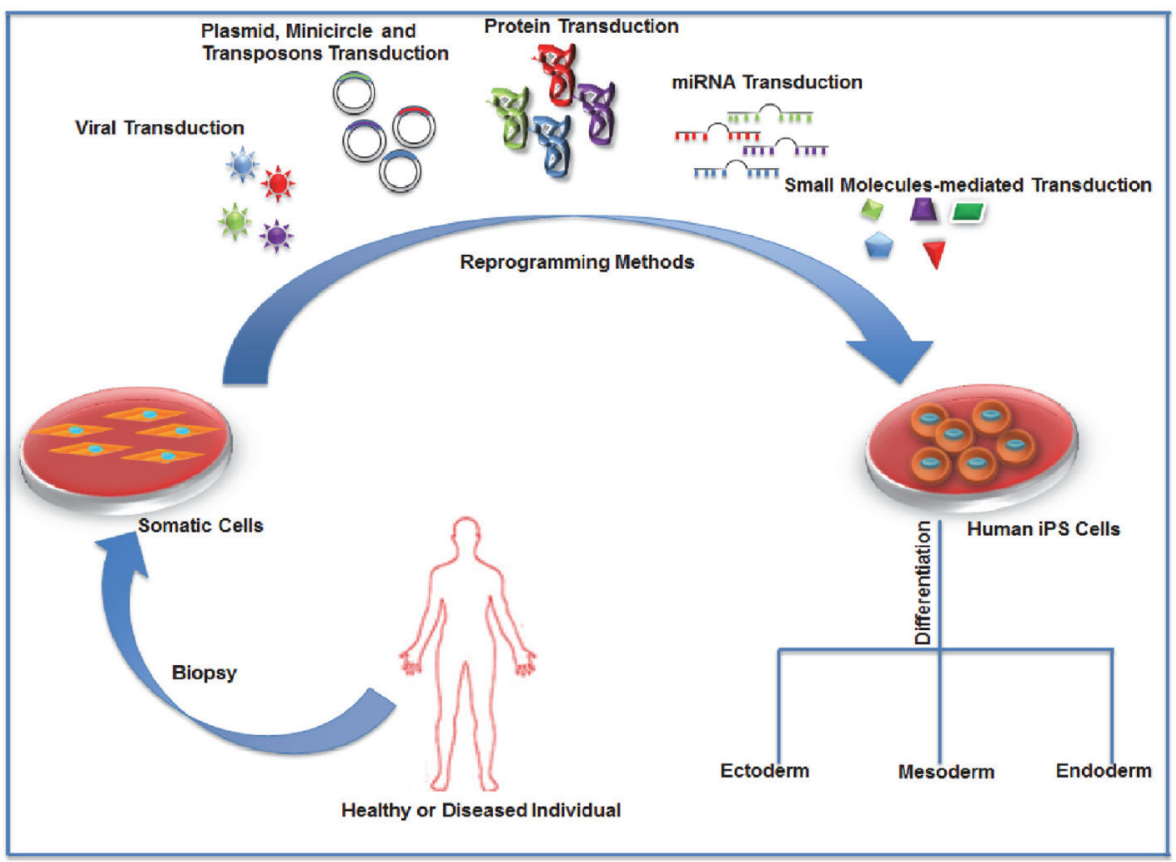

Figure 1.

Schematic showing generation of human induced pluripotent stem cells from somatic cells of a healthy or diseased individual. The somatic cells can be directly reprogrammed into hiPSC by insertion common iPSC reprogramming factors via various methods: viral transduction, plasmid, minicircle and transposon transduction, protein and microRNA transduction methods and small molecules mediated transduction. The hiPSCs thus obtained have the potential to differentiate into any cell type of the human body via multiple lineages: ectoderm, endoderm and mesoderm. 

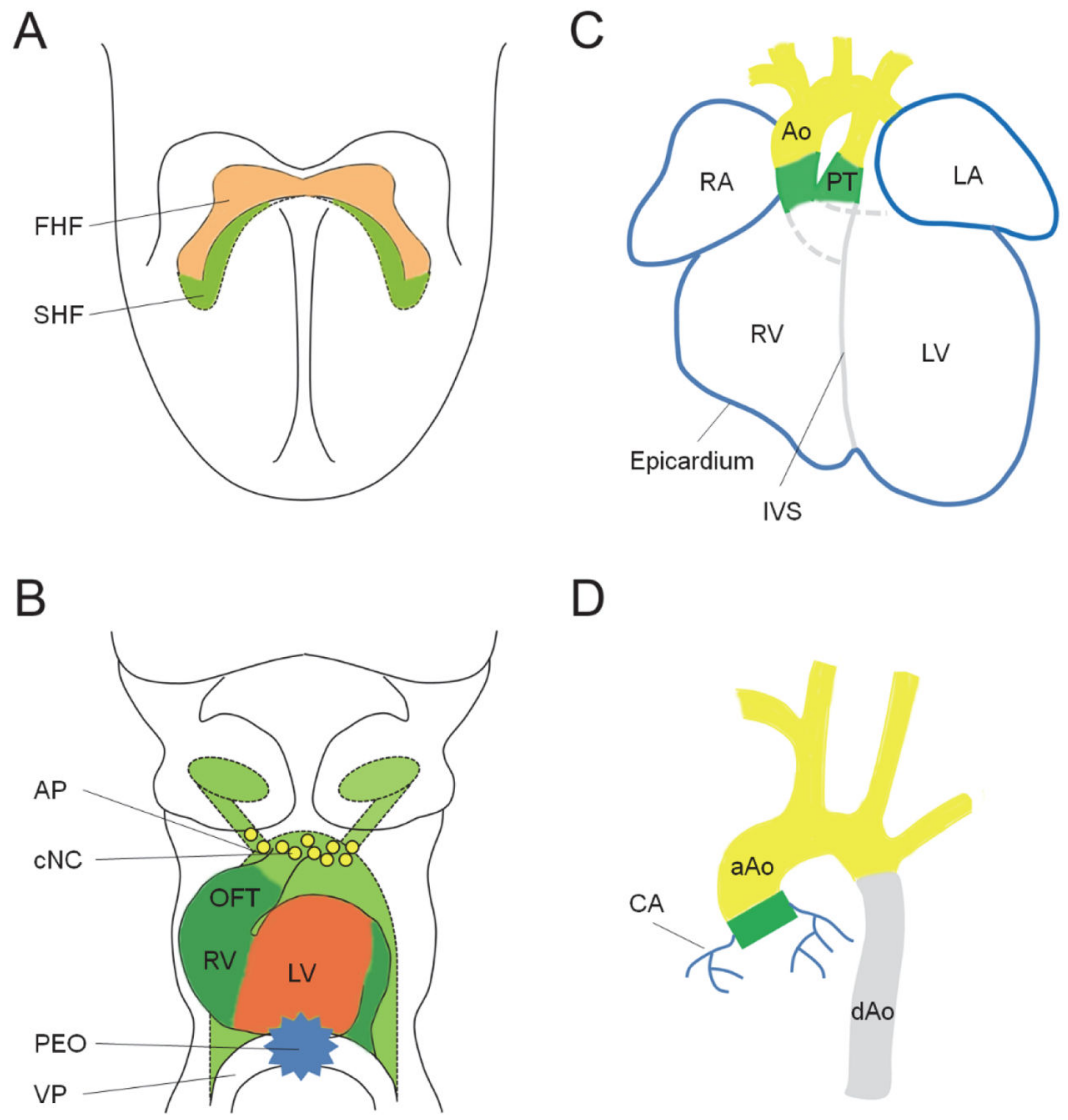

Figure 2.

Embryonic origins of VSMCs in the developing cardiovascular system. A) First heart field (FHF, red) and secondary heart field (SHF, green) contribute to the formation of the linear primitive heart tube. B) As the heart tube begins to loop, FHF mainly contributes to early left ventricular myocardium (red), whereas SHF contributes to the myocardium of the outflow tract (OFT, dark green), early right ventricle (RV, dark green) and part of arterial pole (AP) vascular endothelial cells (light green). Cardiac neural crest (CNC, yellow) cells migrate to the arterial pole (AP) for OFT remodeling, whereas the proepicardial organ (PEO, blue) forms around the venous pole (VP) for the development of the epicardium and coronary vessels. C) The looped mature heart with correctly separated ventricles and atria derived from both heart fields. PEO gives rise to the epicardial cells (blue) that cover the outer layer of the heart. SHF (dark green) contributes to VSMCs at the root of the aorta (Ao) and pulmonary trunk (PT), whereas cardiac neural crest (yellow) contributes to VSMCs in the ascending aorta, aortic arch and pulmonary trunk. RA, right atrium; LA, left atrium; RV, right ventricle; LV, left ventricle; IVS, interventricular septum. D) VSMCs in the ascending aorta (aAo) and aortic arch arise from cardiac neural crest (yellow), whereas SMCs in the descending aorta (dAo) derive from somites (grey). In addition, SMCs in the aortic root originate from SHF (dark green), while coronary arterial (CA) SMCs arise from the PEO (blue). 


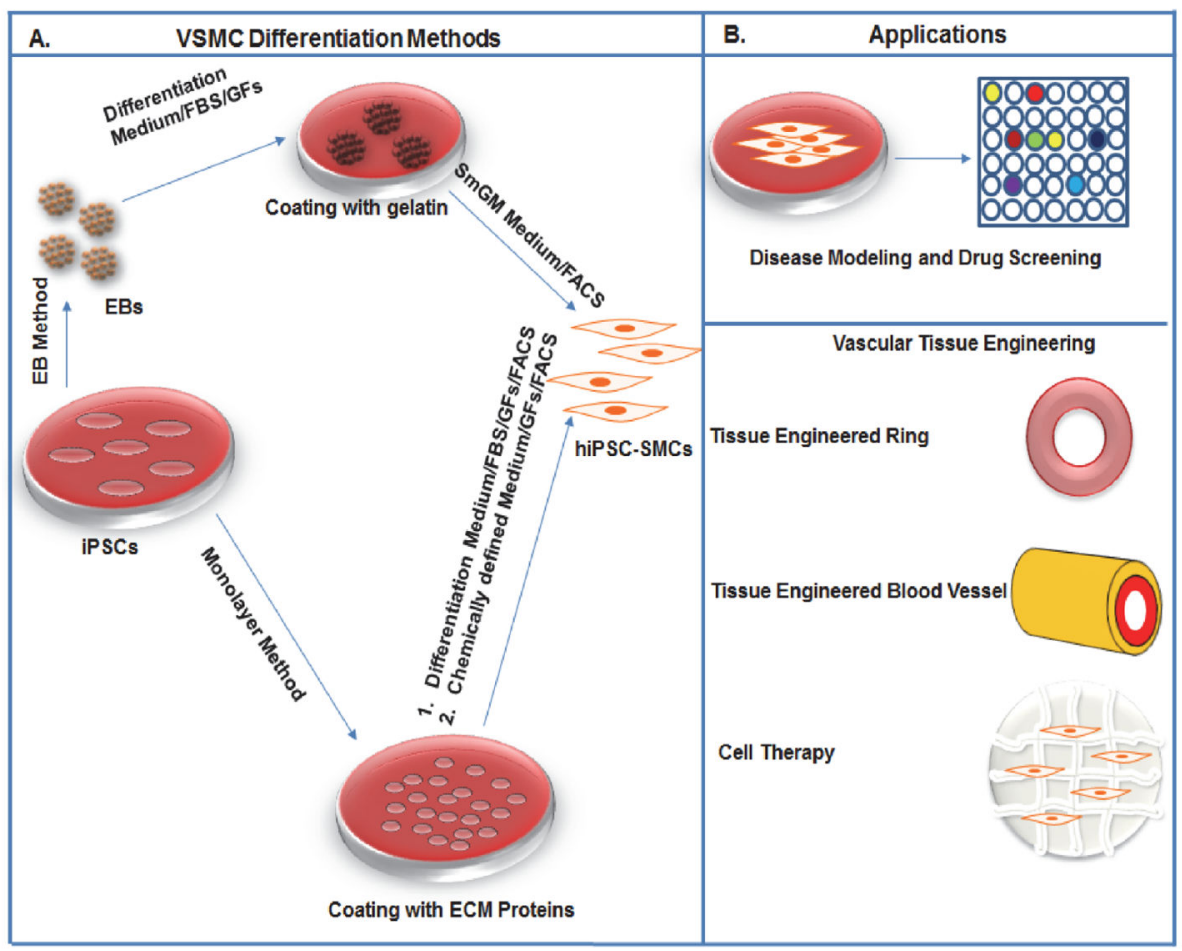

Figure 3.

Schematic showing different methods to derive VSMCs and their regenerative applications. (A) The figure explains two major methods: 1) EB and 2) Monolayer to derive VSMCs. The EBs were initially plated on a gelatin coated plate and cultured in a differentiated medium containing FBS and finally differentiated using commercially available smooth muscle medium (SmGM). FACS have been used to sort VSMCs in some methods. In the monolayer method the iPSCs culture on ECM coated plated and further differentiated either using a chemically defined medium containing growth factors (GFs) or a differentiation medium with FBS and GFs. These cells were further sorted using FACS to get pure VSMCs. (B) The figure shows various regenerative applications of VSMCs derived from human iPSCs: disease modeling and drug screening and tissue engineering applications. 